EGU2020-6247

https://doi.org/10.5194/egusphere-egu2020-6247

EGU General Assembly 2020

(c) Author(s) 2021. This work is distributed under

the Creative Commons Attribution 4.0 License.

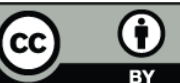

\title{
Possible Effects of Climate Change on New Zealand Design Wind Speeds
}

\author{
Amir Ali Safaei Pirooz ${ }^{1}$, Richard G.J. Flay ${ }^{2}$, Richard Turner ${ }^{3}$, and Cesar Azorin-Molina ${ }^{4,5}$ \\ ${ }^{1}$ Department of Mechanical Engineering, The University of Auckland, Auckland, New Zealand (asaf433@aucklanduni.ac.nz) \\ ${ }^{2}$ Department of Mechanical Engineering, The University of Auckland, Auckland, New Zealand (r.flay@auckland.ac.nz ) \\ ${ }^{3}$ NIWA, Wellington, New Zealand (richard.Turner@niwa.co.nz ) \\ ${ }^{4}$ Centro de Investigaciones sobre Desertificación - Spanish National Research Council (CIDE-CSIC), Moncada (Valencia), \\ Spain (cesar.azorin@uv.es) \\ ${ }^{5}$ Regional Climate Group, Department of Earth Sciences, University of Gothenburg, Gothenburg, Sweden \\ (cesar.azorin@uv.es)
}

The climate is changing, and as a result, the Earth could experience more severe extreme weather events. Growing interest and concern about the effects of climate change on cities, infrastructures and people's lives raises the question "how are design wind speeds influenced by different climate change scenarios?". This study aims at (i) analysing the gust wind records of four meteorological stations across New Zealand for the period 1972-2017; (ii) investigating whether or not the longterm wind gust series have changed significantly; and (iii) how these changes can be considered in the estimation of design wind speeds to ensure the safety and reliability of the future structures.

Historical hourly and daily gust wind speed series recorded at the four selected stations were subjected to a robust quality control and homogenisation protocol to ensure all the artificial inhomogeneities resulting from factors like station relocations, anemometer height changes, instrumentation malfunctions, instrumentation changes, different sampling intervals, and observation environment changes, have been eliminated prior to any subsequent analyses. Then, annual and seasonal trends in both magnitudes and frequencies of the extreme winds were evaluated as to whether the observed trends are statistically significant or not by calculating $\mathrm{p}$ values. From the derived gust trends, some recommendations are proposed for consideration in regard to revising the design wind speeds for calculating the wind loads on structures. In addition, the findings of the study are compared with gust wind speed trends in several other countries and also with IPCC $5^{\text {th }}$ assessment projections for New Zealand [1].

The main findings of this research are summarised as follows:

- The magnitude and frequency of wind gust showed negative (significant for some stations and seasons) trends.

- This result suggests that at this stage no extra multiplier is required to be applied to the New Zealand design wind speeds.

- Additional analyses of the long-term wind gust trends at more stations across New Zealand are 
needed.

\section{Reference}

[1] Ministry for the Environment 2018. Climate Change Projections for New Zealand: Atmosphere Projections Based on Simulations from the IPCC Fifth Assessment, 2nd Edition. Wellington: Ministry for the Environment. 